\title{
Transport and Storage of Food
}

$\mathrm{T}$ HE annual report of the Food Investigation Board* reviews the work carried out in 1933 , which was initiated and inspired by Sir William Bate Hardy, whose death on January 23, 1934, robbed the Board of its Director of Food Investigation at a time when the results of his researches were being more and more applied on the commercial scale in the preservation of foodstuffs. The report refers also to. the death of Sir Walter Morley Fletcher and to the resignation through ill-health of Prof. J. J. R. Macleod; the tenure of Sir Joseph G. Broodbank as chairman of the Board had been extended, and Sir J. Alfred Ewing had been reappointed, and Prof. T. P. Hilditch appointed, members of the Board.

As in previous years, the report is divided into sections dealing respectively with the work carried out at the Low Temperature Research Station, the Torry Research Station and the Ditton Laboratory, as well as at the National Physical Laboratory and the Imperial College of Science and Technology. The researches in progress are briefly described by the actual workers concerned. Some have already been published in detail in the scientific Press, others have not yet been completed. In notices in NATURE of earlier reports of the Board, some of the results obtained by the different research workers have been described in considerable detail. On the present occasion, it appears that it might be more profitable to consider some of the broader aspects of the Board's work, and to review the progress made during the past seventeen years, during which Sir William Hardy had been first chairman of the Board and later director of food investigation, in which position he has been succeeded by the Acting Director, Mr. E. Barnard.

At the recent meeting of the British Association in Aberdeen, Sir Frank Smith delivered the Hardy Memorial Lecture on September 8, taking as his subject the transport and storage of food and the influence of Sir William Hardy's work upon food supplies, especially in Great Britain. In this connexion, reference may be made to the aims of the Food Investigation Board, with its annual expenditure of about $£ 45,000$, which are not always fully understood. The Board's object is, and always has been, the improvement of the nation's foodsupply, of which a considerable part is derived from overseas. However, while the source of a particular foodstuff is not the primary consideration, preference is accorded first to home-grown produce, then to that of the Dominions and other

* Department of Scientiflc and Industrial Research. Report of the Food Investigation Board for the Year 1933. Pp. ix +248 . (London : H.M. Stationery Office, 1934.) 4s. net. oversea parts of the Empire and finally to foreign produce. It follows that much of the work which finds a place in the Board's programme is intended to find its application abroad. Great importance is attached to increasing our knowledge of the fundamental properties of foodstuffs, since it is from such work that large advances in the technique of storing and transporting food must be looked for. The principle of gas-storage, for example, was established as the result of a purely scientific inquiry into the phenomenon of dormancy in seeds. The results of such work are, of course, of universal application ; moreover, it is impossible to predict in what direction they will find application. For example, the results of work on the oxidative changes in the fat of beef and mutton have been applied in the storage of butter, of bacon and of vegetable oils. Much fundamental work required for the needs of our own people cannot be carried out here because the experimental material is unobtainable, so that it is the Board's task to promote this where it can best be done. An obvious example is the physiology of tropical and semi-tropical fruits.

The principal foodstuffs on which researches have been carried out are meat, bacon, fish and fruit and vegetables. Seventy years ago, no one in Great Britain had tasted lamb from New Zealand, since it could not be transported and remain fit for food. In 1932, Great Britain imported 7 million pounds' worth of lamb from New Zealand, and this was only about a tenth of the total meat imports. The possibility of importing meat in an edible condition is due to the use of cold as preserving agent. But the satisfactory use of refrigeration depends on a number of factors apart from the maintenance of the requisite degree of cold. Thus cleanliness in handling the carcases is of the utmost importance. The time of hanging before and after refrigeration must also be considered. Hence it is necessary to know exactly what happens in muscle (meat) from the time the animal is killed to the time the meat reaches the consumer, the behaviour of the constituents of the muscle during autolysis, and during freezing and thawing, and the effect of the growth of micro-organisms upon them, before it is possible to specify the correct conditions of storage and transport, with which the refrigerating engineer must comply. When Sir William Hardy started his work on food preservation, he found that the science of refrigeration had grown at a rapid rate, but on the biological side advance had been slow. He initiated a large expansion in the biological research on foodstuffs, the results of which have already borne fruit in commercial practice. 
One of the disadvantages of freezing, especially of beef, is the occurrence of drip when the meat is thawed, due to the formation of ice crystals between the muscle fibres which break them up, and so prevent the reabsorption of the water when the meat is thawed. With very quick freezing, the ice is formed within the fibres and the size of the crystals is diminished, with the result that the drip is less when the meat is thawed. However, the requisite rate of freezing is so high that it is unattainable in pieces of meat thicker than about $2 \frac{1}{2}$ in. Once frozen, moreover, the meat must be kept at a lower and therefore more expensive level of temperature than usual, namely, not higher than $-20^{\circ} \mathrm{C}$. For short periods of storage, chilling, that is, storage at $-1^{\circ} \mathrm{C}$, is a satisfactory method of preserving meat, provided that the carcases are relatively clean bacteriologically. Beef from South America can be kept chilled for so long as five weeks, but up to the present it has not been found feasible to import chilled beef from Australia and New Zealand.

Recently, however, it was demonstrated on a semi-commercial scale at the Low Temperature Research Station that beef can be held in perfect condition in the chilled state for so long as 60-70 days in an atmosphere containing 10-20 per cent of carbon dioxide. This doubling of the life of the meat is due to inhibition of the growth of microorganisms. The laboratory experiments have been fully verified by large-scale experiments at sea and, last year, a consignment of chilled beef in good condition reached Great Britain from New Zealand. The process of gas-storage will also probably be of value to the importers of chilled beef from South America since it seems likely that the use of carbon dioxide will enable the temperature of carriage to be slightly raised and so prevent the formation of any ice in the meat, as occurs under present conditions. It is not possible to raise the concentration of carbon dioxide above 20 per cent since higher concentrations affect the bloom of the meat. Bacon and pork, however, can be stored successfully for considerable periods in high concentrations of carbon dioxide.

Researches on the freezing and smoking of fish were described in the report for 1932 (see NATURE, $132,736 ; 1933)$. Hitherto the resources of the Torry Research Station have been almost wholly engaged in dealing with white fish, but a start has now been made with work on the herring. Modern taste requires a mild salt-cured fish, both for the home market and also perhaps for markets overseas. It has been found that fish with the authentic rich cured flavour can be produced with a much smaller concentration of salt in it than in hardcured fish, namely, 5 instead of 15 per cent, a level at which only some 10 per cent of the water has been extracted. These cured herrings can be cooked without previous steeping in water and are almost as soft as fresh herrings. However, these mildcured fish will not keep unless chilled or frozen : the combination of salting and chilling appears to possess distinct commercial possibilities. It has also been found that herrings rapidly frozen in cold brine and stored at a low temperature will retain their quality for several months, and that kippers made from such herrings are barely distinguishable from those made from the freshest fish. It may be possible therefore to replace herrings imported during the late winter and spring for kippering by home-caught fish which has been brine-frozen and cold-stored earlier in the year. Here it may be mentioned that a new wing of the Torry Research Station containing seven cold chambers in which the temperature can be maintained at $0^{\circ}$ to $-23^{\circ} \mathrm{C}$. was opened by Lady Smith on September 10.

Turning now to fruit, the report points out that little more can be done with imported fruit than to maintain the survey of wastage which is carried out from the Covent Garden Laboratory. The keeping quality of a fruit depends not only on the variety, but also on the stock, soil, climate, cultivation and maturity at the time of picking. The results of storage trials carried out with English varieties grown under English conditions are not applicable to varieties grown overseas under conditions which are generally different to a significant degree : it follows that each area of production must undertake such work for itself, since it cannot be done elsewhere. Most of the work on the cold-storage of fruit is of direct value to the home producer, but only of indirect value to the oversea producer; and this is even more true in the case of gas-storage.

Different varieties of English apples show a remarkable individuality in response to atmospheres containing different proportions of oxygen and carbon dioxide : only a few are suited by an atmosphere containing 10 per cent carbon dioxide with a corresponding diminution in the amount of oxygen, an atmosphere, that is, that can be obtained by regulated ventilation. Other varieties require atmospheres which raise problems in the construction of efficient gas-tight stores. In this connexion, it must be pointed out that research in biological engineering forms an important part of the work of the Food Investigation Board. In the experimental hold at the Ditton Laboratory, it has been possible to compare the efficiency of the different systems of refrigeration in current use, to evaluate such practically important biological constants as the thermal capacity of a stack of apples, the rates at which it generates heat and carbon dioxide, together with the rate 
of evaporation from it, and to study also the transfer of heat from fruit to air and from air to pipes. Such work is of direct value to British shipping in the transport of foodstuffs and to home producers who may wish to store their produce.

The effect of carbon dioxide in the atmosphere is not only to depress the post-climacteric respiratory activity of the fruit, but also to delay markedly the occurrence of the climacteric itself. (The climacteric is the sudden critical change in the life of the fruit when respiratory activity is doubled, and flavour and aroma are developed, the fruit attaining maturity shortly afterwards.) Apples, bananas, peaches and pears produce a substance which stimulates the onset of the climacteric in other fruit which have not yet reached this stage, but oranges and grapes do not. With the progress of senescence of apples in air, there is a steady rise in the amount of alcohol and acetaldehyde present: in an atmosphere containing little oxygen, the accumulation of these substances is slowed, so that the life of the fruit is correspondingly extended. A relationship has been found in apples between the incidence of the climacteric, the time at which the fruit is placed in cold-storage and the occurrence of low temperature breakdown. The incidence of the latter was by far the greatest in fruit transferred to cold store at the peak of the climacteric rise in respiratory activity : unfortunately, there is no practical means as yet whereby growers can detect when their fruit enters the climacteric.

These are a few of the directions, indicated by Sir Frank Smith in his lecture at Aberdeen, in which our knowledge of the properties of foodstuffs is advancing. Such knowledge can only be of inestimable benefit to mankind, and will be for ever associated with the name of the late Sir William Hardy.

\section{Mathematical Aspects of the Propagation of Light*}

By Prof. H. M. Macdonald, o.B.e., F.R.s.

$\mathrm{F}^{\prime}$ ARADAY, like Fresnel, appears to have thought of light in terms of geometrical relations, while Maxwell sought to construct a mechanical model the motions of which will resemble those which constitute light.

Starting from Faraday's ideas, the problem of the propagation of a magnetic disturbance in free space can be approached in a direct manner. There are three vectors involved-the electric current at a point in the space, the magnetic force at the point, and the electric force at the point. The relation between the electric current and the magnetic force is given by Ampère's law, and the relation between the magnetic force and the electric force is given by Faraday's law. It should be noted that Ampère's law was established initially for steady electric currents ; its extension to the case where the electric currents are varying is a result of Faraday's work. Assuming, with Faraday, that the phenomena of light and of electricity have a common origin, Fresnel's law of transversality, that the vectors which specify the disturbance are perpendicular to the direction of propagation, will hold for the propagation of an electric or a magnetic disturbance as well as for light.

These three laws are sufficient to determine the circumstances of the propagation of a magnetic disturbance in free space. It follows that for plane waves the direction of the vector $j$, the time rate of increase of which is the electric current, at a point coincides with the direction of the electric

"From the presidential address entitled "Theories of Light" to Section A (Mathematical and Physical Sciences) of the British Association, delivered at Aberdeen on September 7 . force $E$ at the point, and the relation between $E$ and $j$ is $E=4 \pi V^{2} j$, where $V$ is the velocity of propagation of a magnetic disturbance in free space. Further, if the changes which constitute the disturbance satisfy the laws of dynamics, the potential energy per unit of volume is $\frac{1}{2} E j$-that is, $E^{2} / 8 \pi V^{2}$ in electromagnetic units-and, if $E_{1}$ is the same electric force in electrostatic units, the potential energy is $E_{1}^{2} / 8 \pi$; therefore $E=V E_{1}$, that is, the velocity of propagation is the velocity by which an electric force expressed in electrostatic units must be multiplied to convert it into electromagnetic units; or since the product of an electric charge and the electric force on it, being a mechanical force, is the same in both systems of units, the velocity of propagation is the velocity by which an electric charge expressed in electromagnetic units must be multiplied to convert it into electrostatic units.

The Lagrangian function of the changes which belong to the propagation of an electric or magnetic disturbance in free space is the difference of a kinetic energy function and a potential energy function. The potential energy function is the function given above-the kinetic energy function depends on the electromagnetic momentum and the electric current at a point; the contribution from an element in the neighbourhood of a point cannot be expressed in terms of one vector: it depends on the electric currents throughout space. On this theory, the rate of transfer of energy from a source emitting waves of one frequency is steady, and not oscillatory as on an elastic solid theory.

Consistently with the foregoing, the effect of 